\title{
Lenguaje, ideología y poder: posicionamientos desde la Pragmática y el Análisis Crítico del Discurso
}

\author{
Language, ideology and power: positionings from the Pragmatic and \\ Critical Discourse Analysis
}

Tatiana Marisel Pizarro tatianamariselpizarro@gmail.com

http://orcid.org/0000-0002-3701-5156

Instituto de Investigaciones Socioeconómicas;

Facultad de Ciencias Sociales; Universidad Nacional de San Juan/ Consejo Nacional de Investigaciones Científicas y Técnicas (Argentina)

\section{Resumen}

El estudio de la lengua en uso ha sido abordado por diversas corrientes, cada una con una perspectiva característica: están las descriptivas -que detallan componentes de la lengua-, las normativas -que defienden el respeto riguroso a la gramática-, aquellas con análisis estructurales -que proponen un desmembramiento de la lengua en formas autónomas y observables- y las pragmáticas -en las que se observa cómo los emisores del texto implícitamente manifiestan sus opiniones sobre el tema abordado en contextos sociales, políticos, históricos y culturales-. Con la masividad de los medios de comunicación y el acceso a la información que brindan las nuevas tecnologías, el presente artículo pretende hacer una reflexión teórica acerca de cómo en los actuales contextos culturales y prácticas sociales, la Pragmática y el Análisis Crítico se centran en estudiar el modo en que el orden social regula la 
producción de discursos, su circulación y valor desigual según el poder de los grupos dominantes, acciones que van más allá de tareas analíticas de corte semántico.

Palabras claves: Pragmática; Análisis Crítico del Discurso; discursos.

Abstract

The study of the language in use has been approached by diverse currents, each one by a singular perspective: there are the descriptive ones -which detail components of the language-, the regulations -which defend the rigorous respect to the grammar-, those with structural analysis -which propose a dismemberment of the language in autonomous and observable forms- and pragmatic ones -in which it is observed how the issuers of the text implicitly express their opinions about the topic approached in social, political, historical and cultural contexts-. With the mass media and the access to the information that there offer the new technologies, the present paper intends to make a theoretical reflection about how in the current cultural contexts and social practices, Pragmatics and Critical Discourse Analysis create links that allow us to analyze how the social order regulates the production of discourses, their circulation and unequal value according to the power of the dominant groups, actions that go beyond semantic analytic tasks.

Keywords: Pragmatic; Critical Discourse Analysis; discourses.

En la actualidad, la relevancia de la comunicación mediática es incuestionable. Los medios de comunicación conforman un cúmulo de soportes tecnológicos cuya función social se centra en divulgar informaciones relacionadas a hechos que tienen lugar en el mundo-espacio público (Charaudeau, 2003: 16). Son estos medios los que tienen un rol fundamental en la configuración de la cultura moderna, convirtiéndose de este modo en mediadores entre la realidad y la sociedad. Al respecto, Van Dijk indica que "en las sociedades industrializadas, los medios de comunicación son la institución principal de (re)producción ideológica, probablemente más importante que el sistema educativo propiamente dicho" (1987: 53). 
Para estudiarlos, investigadores de distintas áreas de las ciencias sociales -lingüística, filosofía, sociología, antropología, comunicación, etcétera- conformaron un método interdisciplinario que permitiera un estudio cabal de estos mensajes: el Análisis del Discurso.

El primer investigador que emplea este concepto fue Zellig Harris (1952) en "Discourse analysis". Postula el término como la denominación apropiada para un método analítico que continúe con la lingüística descriptiva más allá de los límites de una frase en particular y, en simultáneo, poniendo en relación la cultura y el lenguaje (1-2).

Este tipo de análisis permite descifrar una realidad percibida desde diferentes ángulos y respaldada sobre distintas bases. En consecuencia, las categorías de análisis pueden ser ya establecidas o emergentes, o bien, mantener diferentes modos de observar el conocimiento: puede considerarse como una realidad objetiva y estática o como subjetiva, cambiante y dinámica (Bolívar, 2007).

Son muchas las disciplinas que estudian la lengua en uso; como se mencionó anteriormente, en este ensayo el foco estará puesto en la Pragmática y en el Análisis Crítico del Discurso. Esta última corriente corresponde a los cimientos de la lingüística crítica que nació en la década de 1970, concebida actualmente como Análisis Crítico del Discurso (ACD) y cuyos representantes más conocidos son Ruth Wodak, Norman Fairclough y Teun A. van Dijk.

EI ACD cuenta con un compendio de técnicas y estrategias que ayudan al investigador a descifrar la interrelación entre discurso y sociedad, desde un enfoque de compromiso ideológico y crítica social. Esencialmente, permite determinar las imágenes cognitivas del otro y los resultados que estas representaciones ocasionan en las relaciones sociales y, en especial, en la construcción de identidades sociales -así como representaciones del mundo, ya sean reales o imaginarias-. Uno de los objetivos de esta metodología es determinar la influencia que tienen los discursos sobre las formas de pensar-actuar de los interlocutores o la legitimación tanto de sistemas de valores -sociales y políticos- (van Dijk, 2009). En otras palabras, el Análisis del Discurso introduce su caracterización de "crítico" cuando surge el compromiso del investigador en la búsqueda de develar las estructuras de poder. Es el ACD el que otorga al público aptitudes críticas-reflexivas de la información que reciben, es el que permite desentrañar las ideologías subyacentes en el discurso, como resistencia contra la desigualdad social.

Al respecto, Teun A. van Dijk (1999) postula que:

La «crítica» a la que se refiere el adjetivo "crítico» en el ACD va sin embargo más allá de las conocidas vigilancia y autocrítica profesionales. Los investigadores críticos no se 
contentan con ser conscientes de la implicación social de su actividad (como cualquier sociólogo de la ciencia lo sería), sino que asumen posiciones explícitas en los asuntos y combates sociales y políticos. Y lo hacen no sólo como ciudadanos, sino también en tanto que, precisamente, investigadores. Aspiran a producir conocimiento y opiniones, y a comprometerse en prácticas profesionales que puedan ser útiles en general dentro de procesos de cambio político y social, y que apoyen en particular a la resistencia contra el dominio social y la desigualdad. Lo cual significa que los investigadores críticos con frecuencia estarán al lado de los distintos grupos y gentes socialmente dominados en el mundo, por los que preferirán trabajar y con quienes se declararán solidarios (p. 24).

El Análisis Crítico del Discurso permite visibilizar las relaciones existentes dentro de un grupo social. Con esto, procura ofrecer un enfoque del modo en que las relaciones sociales son dependientes de la identidad individual o de los grupos sociales -y su respectiva identidad-. Este tipo de metodología permite concebir aquellos mensajes subyacentes en los decires del emisor, así como en los segmentos discursivos que emplea. A través del ACD se puede comprender la posición personal que dicho emisor adopta ante hechos sociales contextualizados. Por esto, siguiendo a Teun A. van Dijk (2005), cabe señalar que el conocimiento es imprescindible para la acción, la interacción, el discurso y las prácticas sociales.

Es claro que la mayoría de las personas conoce acerca de las realidades que acontecen en la sociedad por medio de lo que ha leído en los diarios -virtuales o impresos-, escuchado en la radio o visto en la televisión. De este modo, serán distintas las apreciaciones, opiniones o acciones que surgirán de cada una de esas realidades de acuerdo cuál sea la fuente de información. Se debe poner énfasis, entonces, en que la emisión del discurso no se divorcia nunca de la intencionalidad de los emisores, ya que estos "no producen oraciones correctas descontextualizadas gramaticalmente: ellos tienen razones para decir algo, y para decirlo en la manera en que lo dicen" (Thompson, 2004: 8).

En todos los niveles del discurso es potencialmente posible descubrir indicios que dejan ver algunas de las particularidades sociales de los participantes -sexo, clase, etnia, edad, origen, posición y algún otro modo de pertenencia grupal- y sus contextos sociales. En este ensayo, se adopta la definición de contexto de Van Dijk (1999), que lo precisa como "la estructura de aquellas propiedades de una situación comunicativa que son ostensiblemente relevantes para los participantes en la producción y comprensión de un texto o una conversación" (p. 291). En su definición, Van Dijk valida la correspondencia entre los actos comunicativos y las situaciones condicionadas socialmente donde ocurren. Dicha dependencia permite aceptar 
representaciones mentales de una realidad bajo la premisa de que no son estáticas ni universales, sino que más bien reflejan valores e ideologías personales junto a circunstancias histórico-temporales. En otras palabras, el contexto es dependiente culturalmente.

Es importante, entonces, mencionar ante este tópico a Clifford Geertz y sus estudios sobre el origen de los símbolos y el imaginario colectivo. En su obra La interpretación de las culturas define lo cultural como "el sistema de concepciones expresadas en formas simbólicas, por medio de las cuales la gente se comunica, perpetúa y desarrolla su conocimiento sobre las actitudes hacia la vida". Para Geertz, la ideología es imprescindible en la cultura de un grupo social, su relevancia radica en "la capacidad de aprehender, formular y comunicar realidades que se sustraen al templado lenguaje de la ciencia" (1987: 184).

En este ensayo, es oportuna la definición de Geertz de ideologías como "mapas de una realidad social problemática y matrices para crear una conciencia colectiva", como "un sistema de creencias para la interpretación del mundo", cuya función será "definir (u oscurecer) las categorías sociales, estabilizar (o perturbar) las expectativas sociales, mantener (o minar) normas sociales, fortalecer (o debilitar) el consenso social y aliviar (o exacerbar) tensiones sociales" (1987: 178). Esta concepción puede servir tanto para justificar el discurso del grupo que controla el poder, como para ejercer resistencia contra la opresión.

En relación con esto, Fairclough (2003) ciñe el contexto cultural a las prácticas sociales. Acentúa que los emisores del discurso "establecen un nexo entre el texto y otros elementos de las relaciones sociales e internas de un texto y su relación externa" (p. 37) con las prácticas sociales particulares de una comunidad o de un grupo. En este punto radica la importancia que adquiere el discurso y su análisis:

Hoy se sabe que el lenguaje no es transparente, sino opaco, que los signos no son inocentes, que la connotación va con la denotación, que el lenguaje muestra, pero también distorsiona y oculta, que a veces lo expresado refleja directamente lo pensado y a veces sólo es un indicio ligero, sutil, cínico (Santander, 2009: 135).

Es preciso, entonces, mencionar en este punto a Foucault, quien transformó el término "discurso" en una indiscutible categoría teórica en las ciencias sociales, principalmente en sus obras El orden del discurso y Arqueología del saber. Según Foucault (1973) los discursos instituyen, ordenan y organizan nuestra interpretación sobre la sociedad, las prácticas sociales, los actores sociales y las relaciones entre ellos, mediante la construcción de versiones que 
contienen valores, opiniones, etcétera. Este autor postula que los poderes dominantes establecen un control sobre los discursos circulantes por medio de diversos procedimientos:

Yo propongo que en toda sociedad la producción del discurso está a la vez controlada, seleccionada y redistribuida por un cierto número de procedimientos que tienen por función conjurar los poderes y peligros, dominar el acontecimiento aleatorio y esquivar su pesada y temible materialidad (pp.11-12).

Foucault (1973) se explaya al especificar que estos procedimientos de exclusión son conocidos: "el primero la prohibición: se sabe que no se tiene derecho a decirlo todo, que no se puede hablar de todo en cualquier circunstancia, que cualquiera, en fin, no puede hablar de cualquier cosa" (p. 12).

Indudablemente, no todos los discursos tienen el mismo valor social o el mismo poder. Esto es porque todo orden social regula su producción, circulación y valor desigual según el poder de los grupos dominantes.

En relación a esto, Bourdieu (1991) propone que la fuerza elocutiva del discurso no radica en la palabra en sí, sino en el contexto social en el que es articulado. En este punto toma importancia el habitus como aquel conjunto de disposiciones, posturas, maneras de hacer (discursivas o no-discursivas), que está en la base de aceptación de la dominación social, que se desarrolla a través del tiempo y que también pueden ser un factor importante en la resistencia al cambio social (p. 86).

En este sentido, es preciso puntualizar que el objeto de estudio del Análisis Crítico del Discurso es toda alocución aceptada como manifestación lingüística con forma y significado, resultado de un proceso mental e interpretado a su vez como práctica social compleja estructurada, jerarquizada, interactuante, con funciones contextualizadas y situadas dentro de una sociedad, de una cultura.

El objetivo social del ACD es crear relaciones teóricas entre los discursos y la sociedad. Asimismo, no sólo se ocupará específicamente del análisis de los mecanismos lingüísticos utilizados por el emisor, sino del contexto social en que se inscribe el discurso y sus mecanismos de reproducción. Como se mencionó, el ACD tiene ingente interés en las problemáticas sociales desde una perspectiva crítica. Su enfoque está puesto sobre las relaciones de poder, en las que es apreciable el binomio de dominante-dominado existente en los grupos sociales. 
En este sentido, por ejemplo, las notas periodísticas como interacciones socialmente aceptadas son un corpus interesante de análisis, ya que es perceptible cómo en sus discursos favorecen específicamente a los grupos con poder. Pero es clave mencionar que el lenguaje, en sí, no posee poder propio; lo alcanza mediante el uso que se hace de él. Para su comprensión es fundamental la adopción de un enfoque multidisciplinar que dé cuenta del mundo y del contexto en el que el discurso opera. Para conseguirlo, es necesario interiorizarse en el fenómeno de la intertextualidad que permite en los diversos textos prestar atención en aquellos indicios de lucha de discursos enfrentados para conseguir el predominio.

Con frecuencia, la investigación crítica es cuestionada al ser calificada como política y, por ende, acientífica. Los referentes del ACD refutan esta afirmación, resaltando que toda investigación es política en su sentido más amplio, aunque a simple vista no parezca que indaga sobre problemas sociales.

Como se mencionó anteriormente, el ACD no tiene una metodología específica. Esta corriente ha tomado como referencia en el análisis de las estructuras lingüísticas de poder a la línea gramática funcional sistémica de Halliday, la retórica clásica, la sociolingüística, autores como Michel Foucault y Jürgen Habermas, entre otros. Cada una de esas referencias está presente en mayor o menor medida en el ACD.

Las investigaciones que cuentan al ACD como metodología van más allá de la interpretación de una simple oración gramatical porque conciben que analizar sólo las unidades gramaticales es exiguo para develar cómo funcionan los textos en sus respectivos contextos, los cuales son necesarios investigar. Realizar un ACD requiere gran trabajo por parte del investigador, ya que:

\footnotetext{
Existen ideologías en el discurso que aparecen de manera explícita, éstas son visibles y fáciles de detectar, pero cuando las ideologías se expresan de manera implícita o indirecta, escondida o menos obvia, es cuando ocupa su lugar el Análisis Crítico del Discurso (Jäger, 2008: 503).
}

Luego de este recorrido, nada absoluto, para la comprensión del análisis del discurso, se puede concordar con Adriana Bolívar (2006) en su planteo del discurso como "interacción social", donde los significados son creados, impulsados y transformados en el contexto de lo social.

\section{Las desigualdades desde el Análisis Crítico del Discurso}


Los medios construyen realidades personales y grupales (Fairclough, 1995). La construcción de realidades sociales en torno a ciertos grupos fundamenta las relaciones de convivencia entre segmentos de la población. En virtud de esta premisa, la formulación de implicaciones y la perpetuación de estereotipos generan igualmente algunos parámetros que orientan cómo los individuos se relacionan y cómo dichos individuos utilizan la lengua para promover sus relaciones sociales. La lengua refleja las instancias de poder y los niveles de relaciones sociales en la población. En consecuencia, la lengua refleja las consideraciones sobre el otro, el diferente y sobre los miembros asignados artificialmente a ciertos grupos sociales. De esta forma, los resultados de una investigación sobre el uso particular de la lengua revela el tratamiento que ciertos grupos dan a la población en general.

La lengua -por ende, los discursos- ayuda a que las comunidades reflexionen en torno a sus relaciones sociales en todos los niveles, sin diferenciar a los miembros de dichas comunidades ni a los actantes de dichas interacciones. Se ayuda a determinar cómo la manipulación de los hechos construye realidades en torno a ciertos grupos de la población.

El proveer evidencias concretas sobre el uso de la lengua escrita en las noticias permite concientizar a la población sobre el enfoque que ciertos periódicos usan para reproducir hechos sociales que envuelven a las minorías y permite otorgar herramientas para una lectura crítica de las noticias.

Ahora bien, los discursos no existen aislados, no existen con independencia de otros, "nunca un discurso existe por sí mismo sin estar anclado en algún otro" (Iníguez, 2006: 113). Ciertamente, entre los discursos se da una interrelación, una "intertextualidad". Por otra parte, todo enunciado, todo discurso, está históricamente condicionado. "El discurso es lenguaje como práctica social determinada por estructuras sociales" (Ibídem: 126). Lo que significa que el lenguaje es una parte de la sociedad y no algo externo a ella; es un proceso social; es un proceso condicionado socialmente, históricamente, en el mismo sentido que lo son otras partes o procesos no lingüísticos (Ídem).

El Análisis del Discurso "es un campo de estudio nuevo, interdisciplinario, que ha surgido a partir de algunas otras disciplinas de las humanidades y de las ciencias sociales, como la lingüística, los estudios literarios, la antropología, la semiótica, la sociología y la comunicación oral" (Van Dijk, 1990: 35). Es una disciplina que se interesa por los contextos del discurso, los procesos cognitivos de la producción y la recepción de este, y por los contextos socioculturales del uso de la comunicación. Su principal objetivo es producir descripciones del discurso en un texto y contextos determinados (contexto cognitivo, social, cultural o histórico). 
En cuanto a su relación con la sociedad y la cultura, Van Dijk plantea que "sólo podemos comprender la importancia del discurso en los procesos sociales y en las relaciones de poder contemporáneos si reconocemos que el discurso constituye a la sociedad y a la cultura, así como es constituido por ellas" (Van Dijk, 2005: 399).

Por lo demás, "lo característico del Análisis Crítico del Discurso es que toma partido a favor de los grupos oprimidos en contra de los grupos dominantes, y que manifiesta abiertamente la vocación emancipadora que la motiva" (Fairclough y Wodak. 2005: 368). El ACD se ocupa de problemas sociales y de cuestiones políticas. Del poder social de grupos y/o instituciones. Del control del discurso (político, académico, público, corporativo), por parte de clases dominantes. Analiza la reproducción del dominio y la desigualdad social y la resistencia contra ellas. Obsérvese con todo que el discurso no es sólo un recurso más entre otros: quienes controlan el discurso público controlan ampliamente la mentalidad social e indirectamente la acción pública; y, por consiguiente, controlan también la estructura social (Van Dijk, 1999: 34).

En concreto, el ACD se dirige más hacia los problemas o los temas que hacia los paradigmas (Van Dijk, 1997: 15). Enfoca su atención en problemas sociales tales como el sexismo, el racismo, el colonialismo, etcétera; se centra igualmente en las relaciones de poder, dominación y desigualdad, así como en la reproducción u oposición (resistencia) a través del texto y del habla.

\section{La Pragmática: yendo más allá del código}

La Pragmática puede definirse como aquella "teoría del significado de las palabras en su relación con hablantes y contextos", que interpreta enunciados y significados que pudieran llegar a estar implícitos (Reyes, 1995: 7). Por su parte, Fuentes Rodríguez presenta a la Pragmática como aquella que se ocupa del uso, "de la relación entre la lengua y todo lo que la rodea, todo lo que hace posible la comunicación humana: codificación, descodificación, inferencia" (2000: 40).

En este sentido, la postura teórica correspondiente a la Pragmática que adoptamos en este ensayo incluye la concepción de "discurso" en su definición:

La Pragmática debe entenderse como la disciplina lingüística que examina todos los elementos que intervienen en la producción y en la interpretación de los enunciados concebidos como actos de discurso por medio de los cuales los interlocutores construyen 
una representación verbal que hace referencia al mundo (nivel temático referencial) manifestando al mismo tiempo una intencionalidad comunicativa (dimensión "ilocutoria" o ilocucionaria). La Pragmática corresponde así a lo que podemos llamar semántica del enunciado (Herrero Cecilia, 2006: 25).

En esta línea, es preciso el estudio de variables como aquellos/as que intervienen en el proceso comunicativo (emisor y destinatario), la situación comunicativa, contexto verbal y la intención comunicativa.

En cuanto al objeto de estudio de la Pragmática se considera al "estudio de los principios que regulan el uso del lenguaje en la comunicación, es decir, las condiciones que determinan tanto el empleo de un enunciado concreto por parte de un hablante concreto en una situación comunicativa concreta como su interpretación por parte del destinatario" (Escandell Vidal, 2002: 13-14).

Mediante la Pragmática se pueden distinguir los componentes materiales -emisor, destinatario, enunciado, entorno- de los relacionales -tipos de nexos desarrollados entre esos componentes materiales- de un intercambio comunicacional. Estos últimos son los que constituyen el objeto de estudio de la Pragmática y pueden ser:

-Información pragmática: conjunto de creencias, supuestos, representaciones y opiniones de una persona durante una interacción.

-Intención: propensión a conseguir un fin último con esa interacción. Por un lado, toma especial importancia la relación que se establece entre el emisor y la información pragmática; y por el otro lado, los nexos entre el destinatario y el entorno.

-Relación social: el emisor elabora sus enunciados en función a sus necesidades, el vínculo con el destinatario y los conocimientos en torno al tema tratado.

\section{Una breve circunscripción histórica de la Pragmática}

La primera mención al término "Pragmática" la hace el semiótico Charles W. Morris (1938) en un artículo. En la línea de Peirce, desarrolló una teoría semiótica en la que daba cuenta de tres tipos de relaciones que adoptaban los signos: sintáctica -relación formal de los signos entre sí; semántica -relación de los signos con los objetos a los que se puede aplicar- y pragmática relación de los signos con los intérpretes-. Estas relaciones daban cuenta de las dimensiones 
que los componen: el signo como vehículo de la comunicación, el designatum -eso a lo que se refiere- y el interpretante. Con esta breve diferenciación da cuenta de una corriente de estudios que supo considerar por primera vez al lenguaje en uso, tal como se manifiesta en toda situación comunicativa en concreto.

Si bien Morris fue el que acuñó el término, el desarrollo de la Pragmática como línea de investigación estuvo de la mano de Austin con su "filosofía del lenguaje corriente", en la que expresaba que "el lenguaje que usamos en nuestra comunicación ordinaria es una herramienta que el paso del tiempo ha ido puliendo, hasta hacer de ella un útil perfectamente adaptado a los fines que sirve" (1988: 44). Así, las distinciones que establece el lenguaje ordinario pueden ( $y$ deben) entenderse como un indicativo de las distinciones que una sociedad ha considerado necesarias. A partir de esta postura teórica, se desvalorizó la lógica verificacionalista (con esta los estudios se reducían a determinar la verdad o falsedad de los enunciados). De este modo, lo que Austin pretendía era determinar el grado de adecuación de los discursos a las circunstancias en los que son emitidos.

Son diversas las teorías pragmáticas que se construyeron desde entonces, pero en esta tesis nos abocaremos al modelo teórico desarrollado por el filósofo H. P. Grice llamado "Principio de Cooperación". Con este modelo, el autor desarrolló una serie de principios no normativos aceptados tácitamente que regulan el intercambio para una conversación coherente y eficaz: máxima de cantidad -lo dicho debe ser lo más informativo posible-; máxima de cualidad -lo dicho debe ser verdadero-; máxima de relación -debe ser relevante- y máxima de modalidad debe ser claro-.

Asimismo, cuando estas máximas no se cumplen, de acuerdo con qué aspecto se da ese incumplimiento pueden ser: violación encubierta -el emisor induce conscientemente al error; supresión abierta -la comunicación se limita porque el interlocutor se niega a colaborar-; conflicto -uno de los interlocutores opta por una de las máximas descripta anteriormente- e incumplimiento -hay desprecio por una de las máximas pero sujeción a las otras-.

El modelo teórico de Grice propone la noción de "implicatura" para suplir con estos incumplimientos. De este modo, el autor hace una distinción entre aquello que se dice y aquello que se comunica.

Lo que se dice se manifiesta formalmente en el enunciado valiéndose del código lingüístico y corresponde al contenido proposicional; lo que permite evaluarlo desde una lógica de tipo veritativo-condicional (Escandell Vidal, 2002: 80). Por otro lado, lo que se comunica es toda la información que divulga el enunciado. Es decir, partimos de la base que todos los mensajes 
transmiten algo más que el significado de tal contenido proposicional. Ese "algo más" corresponde a un contenido implícito y es llamado implicatura.

Estas implicaturas pueden clasificarse en convencionales - devienen directamente de los significados de las palabras- y no convencionales - devienen de los factores contextuales- que, a su vez, se subdividen en conversacionales -se explican por factores de la conversación- y no conversacionales -relacionados con factores de naturaleza moral, estética o social-. Por su parte, las conversacionales poseen dos subtipos: aquellas generalizadas, que no dependen del contexto en forma directa, y las particularizadas que dependen directamente del contexto.

Tal como puede verse, las implicaturas son "el camino necesario para reconstruir el auténtico contenido que se ha tratado de comunicar (y restaurar, a veces, la vigencia de las máximas" (Escandell Vidal, 2002: 82).

Pueden resumirse en tres tipos las relaciones entre implicaturas y máximas:

1. Que se dé la implicatura sin que haya una violación aparente: de esta manera lo implícito deviene de su naturaleza convencional -se desprende del enunciado mismo y no es necesario acudir al contexto comunicativo.

2. Que la implicatura se dé, pero infiriéndose que se viola una máxima para evitar un conflicto con otra máxima.

3. Que su existencia se dé porque precisamente se viole una máxima.

\section{Entre lo que se dice y lo que realmente se dice}

Las teorías pragmáticas clásicas, plantea Gutiérrez Ordóñez, "estaban orientadas a satisfacer un interrogante: ¿cuáles son los principios en los que se apoya la inferencia del sentido implícito?" (2002: 50). Era importante expresar cómo se realizaba ese proceso y enumerar sus pasos. En 1986, los lingüistas D. Wilson y D. Sperber erigieron la Teoría de la Relevancia, presupuesto teórico que representó una revolución en los estudios pragmáticos, ya que pretendía completar el Principio de Cooperación de Grice al responder interrogantes como:

- ¿Cómo es posible que el emisor desee decir algo y codifique sólo una parte o manifieste algo que solamente se le parece -metáfora- o, por el contrario, que manifieste lo opuesto a lo que realmente quiere decir -ironía-? 
- ¿Cómo es posible que el receptor -destinatario- pueda dar ese salto desde el "significado literal" al "sentido implícito" del mensaje?

-¿Cómo los destinatarios de los mensajes interpretan las ambigüedades?

Según la Teoría de la Relevancia, comunicarse no sólo es circunscribir el pensamiento en forma de palabras que conlleven a una tarea de codificación-decodificación. Sperber y Wilson plantean que la comunicación humana pone en funcionamiento dos mecanismos:

-El modelo asentado en la codificación-decodificación del código lingüístico, que tienen como objeto de descripción la representación semántica (en el enunciado hay un sentido constante y común).

-El modelo asentado en la ostensión-inferencia, basado en los índices que el comunicador otorga con el objetivo que el destinatario pueda inferir sus propósitos.

Es decir, de acuerdo con esta teoría, nos comunicamos mediante dos vías que se complementan mutuamente para lograr una mayor eficacia comunicativa: el modelo codificado y el modelo inferencial. Según este modelo, quien comunica otorga ciertos indicios sobre su intención de transmitir determinado significado, por lo que el interlocutor deberá inferir a partir de esa evidencia otorgada:

Desde luego, un enunciado es sólo una parte de esa evidencia, un segmento que se ha codificado de forma lingüística, por lo que la comprensión del lenguaje oral implica siempre un factor de descodificación. Pero, en cualquier caso, el significado lingüístico al que se llegue mediante tal descodificación será sólo uno de los inputs que intervengan en un proceso de inferencia no-demostrativa que provocará una interpretación particular del significado del hablante. El cometido de una pragmática de carácter inferencial es explicar cómo el oyente deduce el significado del hablante a partir de la evidencia proporcionada por éste (Sperber y Wilson, 2004).

Estos autores ven a la inferencia como la relación que crea un supuesto a partir de otro. Es decir, Sperber y Wilson ven como "supuesto" aquellos pensamientos que una persona tiene inscritos como representaciones del mundo real a partir de opiniones, creencias o deseos. Entonces, una inferencia es un proceso deductivo que reconstruye la intención del emisor, sobre la que el receptor no tendrá certeza absoluta (Sperber y Wilson, 2004).

Ahora bien, un mensaje es pertinente cuando produce "efectos contextuales"; en otras palabras, "cuando unido a un contexto genera informaciones que no estaban ni en el enunciado 
ni en el ambiente, ni en el texto ni en el contexto" (Gutiérrez Ordóñez, 2002: 54). Esta contextualización corresponde a "efectos cognitivos positivos" siempre y cuando le signifique al receptor una información adicional (Sperber y Wilson, 2004: 240). En esta línea, para que una información sea considerada relevante debe ser un contenido nuevo -desconocido- y que además sea coherente con el contexto.

Entonces, es preciso y oportuno demarcar los ámbitos de ambas disciplinas. Juan Herrero Cecilia (2006) ubica a la Pragmática

dentro del campo de la actividad enunciativa y de la elaboración del enunciado, relacionándose con el estudio de los actos de habla y el estudio de la interacción en el intercambio verbal; sin olvidar el aspecto de la "tematización" o de la dimensión informativa del enunciado (pp.15-16).

Por otro lado, el Análisis Crítico del Discurso enfoca su estudio en

la forma en la que el abuso de poder y la desigualdad social se representan, reproducen, legitiman y resisten en el texto y el habla en contextos sociales y políticos. Con esta investigación disidente, los analistas críticos del discurso toman una posición explícita y, de esa manera, buscan entender, exponer y, fundamentalmente, desafiar el abuso de poder $y$ la desigualdad social. Esta es también la razón por la cual el ACD puede ser caracterizado como un movimiento social de analistas discursivos políticamente comprometidos (Van Dijk, 2016: 204).

El Análisis Crítico del Discurso comparte muchos rasgos con la Pragmática, a pesar de que no muchos autores centren sus estudios en los aspectos contextuales y los contenidos implícitos de los enunciados. Este tipo de análisis -usualmente usado por la Sociología o la Ciencia Política- parte de una metodología lingüística, sin características cuantitativas.

De este modo, el estudio del lenguaje y sus relaciones con la sociedad es planteado como algo inevitablemente interdisciplinar. Sociedad y lenguaje son realidades inherentes. Cada acto de habla bosqueja esa necesidad de contextualización. Independientemente de la posición de poder en la que esté situado el hablante, éste estará condicionado por mecanismos que dependerán de su contexto social, político e histórico. Es decir, el lenguaje no es consecuencia de los procesos sociales, sino que forma parte de ellos. En otras palabras: "primero, la lengua es el interpretante de la sociedad; segundo, la lengua contiene la sociedad" (Benveniste, 1978: 99). 


\section{Reflexiones finales}

El lenguaje cataloga el poder, manifiesta poder y está implicado en los desafíos y luchas para conseguirlo. Como se mencionó, el Análisis Crítico del Discurso tiene inmenso interés en las problemáticas sociales desde una perspectiva crítica. Su enfoque está puesto sobre las relaciones de poder, más precisamente en las relaciones dadas entre los roles de dominados y los dominantes en los grupos sociales.

Por otro lado, la Pragmática va más allá de los límites de la frase, de la acción y de la interacción, para explicar el uso del lenguaje y del discurso en los términos más extensos de estructuras, procesos y exigencias sociales, políticas, culturales e históricas.

Esto se debe a que el discurso es conocimiento para las personas que erigen su discernimiento del mundo y que adaptan sus representaciones a los contextos en los que viven. El discurso es historia, porque para comprender lo que es dicho en el presente es necesario conocer el pasado. El discurso es dialógico porque sus cimientos están fundados en las interacciones. Y, tal como se deseó plantear en este ensayo, es acción, ya que con los discursos erigidos es posible construir y transformar realidades.

\section{Bibliografía}

Austin, J. (1988). Cómo hacer cosas con palabras. Barcelona: Paidós Ibérica.

Benveniste, E. (1978). Problemas de Lingüística General (Tomo II). México: Siglo XXI.

Bolívar, A. (2007). Análisis del discurso, ¿por qué y para qué? Venezuela: Editorial CEC. Recuperado https://www.google.com.ar/search?hl=es\&tbo=p\&tbm=bks\&q=isbn:980388350X

Bourdieu, P. (1991). El sentido práctico. Argentina: Siglo XXI Editores. Recuperado dehttps://sociologiaycultura.files.wordpress.com/2014/02/bourdieu-el-sentidoprc3a1ctico.pdf

Charaudeau, P. (2003). El discurso de la información. La construcción del espejo social. Barcelona: Gedisa.

Escandell Vidal, M. V. (2002). Introducción a la pragmática. Barcelona: Ariel. 
Fairclough, N. (2003). El análisis crítico del discurso como método para la investigación en ciencias sociales. En Wodak, R. y Meyer, M. (Comps.). Métodos de Análisis Crítico del Discurso (pp. 179- 203). Barcelona: Gedisa.

Foucault, M. (1973). El orden del discurso. Ciudad Autónoma de Buenos Aires, Argentina: Tusquets editores.

Fuentes Rodríguez, C. (1999). La organización informativa del texto. Madrid: Arco Libros.

Geertz, C. (1989). La interpretación de las culturas. Barcelona: Gedisa.

Grice, P. (1975). Logic and Conversation. En Davidson, D. y Harman, G. (eds). The Logic of Grammar (pp. 64-75). Encino, CA: Dickenson.

Gutiérrez Ordóñez, S. (2002). La lingüística del habla: de la retórica a la pragmática. Textos de didáctica de la lengua y la literatura, 3, pp. 7-17.

Herrero Cecilia, J. (2006). Teorías de pragmática, de lingüística textual y de análisis del discurso. Cuenca: Ediciones de la Universidad de Castilla.

Jäger, S. (2003). Discurso y conocimiento: aspectos teóricos y metodológicos de la crítica del discurso y del análisis de dispositivos. En Wodak, R. y Meyer, M. Métodos de análisis crítico del discurso. Barcelona: Gedisa.

Reyes, G. (1995). Pragmática y descripción gramatical. En Alvar, M. (dir.). Introducción a la Lingüística española (pp. 433-444). Barcelona: Ariel.

Santander Molina, P. (2009). Por qué, para qué y cómo hacer Análisis del Discurso de los medios de comunicación. En Santander Molina, P. (Ed.). Analizando los medios y la comunicación teoría y métodos. Valparaíso, Chile: Ediciones Universitarias de Valparaíso. Recuperado de http://www.portalcomunicacion.com/pdf/analizando.pdf

Sperber, D. y Wilson, D. (2004). La Relevancia. Comunicación y procesos cognitivos. Madrid: Visor.

Thompson, J. (2004). Lenguaje e ideología. Zona abierta, pp. 41-42.

Van Dijk, T (1990). La noticia como discurso, comprensión, estructura y producción de la información. Barcelona, España: Paidós. Recuperado de https://linguistica2013.files.wordpress.com/2013/11/van-dijk-teun-la-noticia-comodiscurso.pdf

Van Dijk, T (1999). El análisis crítico del discurso. Anthropos, 186, pp. 23-36. Recuperado de http://www.discursos.org/oldarticles/El\%20an\%E1lisis\%20cr\%EDtico\%20del\%20discurs o.pdf

Van Dijk, T (2003). Ideología y análisis del discurso. Utopía y Praxis Latinoamericana. Revista Internacional de Filosofía Iberoamericana y Teoría Social, 29, pp. 9-36. Recuperado de 
http://www.discursos.org/oldarticles/ldeolog\%EDa\%20y\%20an\%E1lisis\%20del\%20disc urso.pdf

Van Dijk, T. (2009). Discurso y poder. Contribuciones a los Estudios Críticos del Discurso. Barcelona: Gedisa.

Wodak, R. y Meyer, M. (2003). Métodos de análisis crítico del discurso. Barcelona: Gedisa. 